\title{
APPLICATION OF THE RE-CYCLING METHOD TO SUPPORT DESIGN FOR AND FROM END-OF-LIFE.
}

\author{
Martínez Leal, Jorge (1,2); \\ Pompidou, Stéphane (1); \\ Charbuillet, Carole (3); \\ Perry, Nicolas (4)
}

1: University of Bordeaux, CNRS, Arts et Métiers Institute of Technology, Bordeaux INP, INRAE, I2M Bordeaux, F-33400 Talence, France;

2: University of Bordeaux, CNRS, Bordeaux INP, IMS, UMR 5218, F-33400 Talence, France;

3: Arts et Métiers Institute of Te

\begin{abstract}
Nowadays, the world is shifting towards a more sustainable way of life, and product designers have an important part in this change. They have to eco(re)design their products to make them environmentally conscious throughout their lifecycle, and especially at their end-of-life (EoL). However, one can observe that synergy between product designers and recycling-chains stakeholders is lacking, mainly due to their weak communication. While many design-for-EoL approaches coexist in the literature, design from EoL must also be taken into account to fully develop a circular economy.

RE-CYCLING is an innovative design approach that supports both design for and from EoL. This paper focuses on the recycling EoL-option and the validation of the associated indicators. To validate the design-for-recycling indicators, the recyclability of three smartphones is assessed. It is expected that indicators provide a similar score as none of them was designed to be recycled; results comply with expectations. In parallel, the convenience of using recycled materials in smartphones is analysed to validate our design-from-recycling indicators. It is found that the proposed indicators can indeed support designers integrating recycled materials in products.
\end{abstract}

Keywords: Design for Recycling, Design from Recycling, Ecodesign, Circular economy, Sustainability

\section{Contact:}

Martínez Leal, Jorge

Université de Bordeaux

I2M / IMS

France

jorge.martinez-leal@u-bordeaux.fr

Cite this article: Martínez Leal, J., Pompidou, S., Charbuillet, C., Perry, N. (2021) 'Application of the RE-CYCLING Method to Support Design for and from End-Of-Life.', in Proceedings of the International Conference on Engineering Design (ICED21), Gothenburg, Sweden, 16-20 August 2021. DOI:10.1017/pds.2021.51 


\section{INTRODUCTION}

Proper management of waste is a key point for avoiding both pollutions of soil and groundwater, and contaminant emissions in the atmosphere. Actions implemented by legislation to encourage the recovery of end-of-life (EoL) products (i.e. waste) follow two different paths. The first one consists of setting up waste treatment chains (European Parliament, 2008). In this context, performance of extended producer responsibility chains shows that some of them are insufficiently adapted to the waste they process. The second route aims to prevent the generation of waste by improving product design (European Parliament, $2009,2012)$. Although an acceleration in the implementation of regulations has been seen in the last few years, we can observe that products are still not systematically designed to be processed at best by their EoL chain (Martínez Leal, 2019). This discrepancy between the product and its EoL treatment is mainly due to the weak communication between its designer and the recovery-chain stakeholders (Maudet et al., 2007). The antagonism is reinforced by the time-lag between the design of the product and its EoL treatment, as well as the geographic performance disparity between stakeholders involved in the EoL chain (Mathieux, 2002). A direct and bijective link between designers and EoL stakeholders must be reinforced (or built if non-existent) to ensure a real circular economy (Lindkvist Haziri et al., 2019; Lindkvist Haziri and Sundin, 2020).

RE-CYCLING is an innovative indicator-based design method that includes both design for and from end-of-life (D2fEoL) (see respective sections 3.1 and 3.2). This combined approach seeks to improve the aforementioned link between product designers and EoL chain stakeholders. It focuses on the designers' point of view, even though an EoL-stakeholders-centred approach could be followed in the same way. Thus, designers are no longer considered only as providers of future waste to the EoL chain, but also as customers of this same chain. Their interest in integrating EoL artefacts (e.g. any refurbished part or module, or of course recycled materials) in a new product is thus stimulated.

In this article, we only focus on validating the indicators of D2f-Recycling (D2fR). Nevertheless, RECYCLING's approach definition, indicators selection and application examples are fully detailed by the authors in previous studies (Martínez Leal, 2019; Martínez Leal et al., 2020).

\section{CIRCULARITY MANAGEMENT BY BOTH DESIGN AND EOL STAKEHOLDERS}

Both design and end-of-life phases of the product lifecycle must be connected to ensure the circularity of components and materials. Therefore, designers must take this into account by designing any product for and from its end-of-life. The corollary is that stakeholders of the product's end-of-life must also change their practices to work from and for the design. The possible approaches and exchanges between design and EoL stakeholders are illustrated in figure 1.

\subsection{Product Designers Approaches}

From the product designer's point of view, two approaches can be followed (see figure 1):

- Design for EoL is the most known and used (Go et al., 2015; Pahl et al., 2007). It aims (i) to improve the product so that it can be recovered in the best possible way when it becomes waste, and (ii) to promote the elimination of residues that could not be recovered;

- Design from EoL is concerned with the integration of artefacts from the end-of-life treatment chain into a new product (e.g. recycled materials instead of virgin ones, reused modules or parts recovered during disassembly, etc.). This innovative approach aims at closing the loop in a circular economy perspective.

\subsection{End-of-Life Stakeholders Approaches}

From the EoL stakeholders' point of view, two approaches can be followed (see figure 1):

- EoL from Design aims to integrate the information accrued from product design into the operating mode of the chain, or its treatment processes to increase functional, material and energy recovery;

- EoL for Design is concerned with the EoL treatment pathway that becomes a supplier of artefacts (i.e. product, module, part or material from any recovery pathway) that must meet the designer's specifications. 


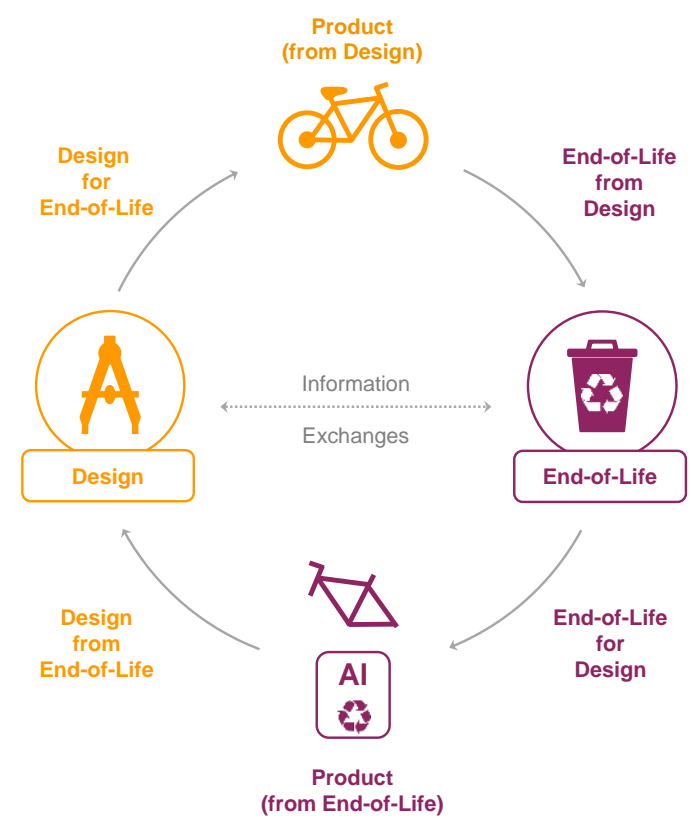

Figure 1. Design and End-of-Life exchanges (Martínez Leal et al., 2020)

\section{THE RE-CYCLING APPROACH}

RE-CYCLING is an innovative indicator-based design approach that includes both design for and from end-of-life (D2fEoL). Although the name might wrongly make one think it only relates to the recycling EoL option, Cycling is intentionally highlighted as it refers to closing the loop and circular economy. Indeed, the method aims at helping (i) EoL stakeholders to recover all or part of the waste value by recovering whole products, modules or parts, recycling materials or producing energy, and (ii) designers to integrate EoL components or materials in a new product. Both are necessarily involved in the possibility of extending artefacts life by integrating them into a $(n+1)$ lifecycle.

\subsection{Design-for-EoL proposal}

\subsubsection{Method description}

The design-for-EoL proposal is the first module of RE-CYCLING. It allows linking product assessment to design guidelines by an indicator-based approach. The objective is (i) to help designers to focus on the product features that need to be improved the most by identifying the least efficient characteristics in terms of EoL recovery, and (ii) to propose appropriate guidelines to improve them. This approach is based on four consecutive steps:

- Step 1: Characterisation of the product. The bill of materials (BOM) of the product being eco(re)designed is set up;

- $\quad$ Step 2: Evaluation of action levers. The designer can activate several action levers to improve the product in anticipation of its EoL. This improvement can take part at several scales (e.g. product, module, elementary part, fasteners, connectors, etc.), within different scopes (accessibility to components or fasteners, circularity of materials, disassemblability of the whole product or its modules, etc.), and always within the legislation frame. Thirty-three performance indicators (each associated with an action lever) are calculated and sometimes aggregated (in different ways);

- $\quad$ Step 3: Identification of product's hotspots. The product's hotspots (i.e. the least performant characteristics) are identified based on step 2 results;

- $\quad$ Step 4: Proposal of relevant guidelines. Each action lever being associated with a set of designfor-EoL guidelines, the most relevant ones are then provided to the designer as support.

\subsubsection{Indicators description}

Indicators used in the RE-CYCLING's design-for-EoL module aim to assess which action levers need to be activated: 
- The materials' compatibility action lever addresses the chemical compatibility of materials throughout their recycling. The overall score is defined as the average of compatibilities of all involved materials assessed by pairs, depending on whether each one is to be recovered, or whether it appears as a secondary one in the EoL treatment (e.g. an impurity that could compromise the recycling of the main constituent);

- The materials' diversity action lever addresses the influence of the variety of materials used in the product being recycled;

- The materials' recyclability action lever addresses the efficiency of recycling. The associated indicator characterises the recyclability of all materials in the product, depending on both material's recycling and purity rates.

- Lastly, the product's recyclability is defined as an average function of compatibility, diversity and recyclability.

Indicators are briefly recalled in Table 1 (from Martínez Leal et al. 2020). They are all expressed in the same way to be easily compared: their value ranges from 0 to 1 , where 1 corresponds to the best score and 0 to the worst.

Table 1. RE-CYCLING's indicators used in the design-for-recycling proposal

\begin{tabular}{|c|c|c|c|}
\hline Indicator & Expression & Parameters & $\begin{array}{c}\text { Main } \\
\text { references }\end{array}$ \\
\hline $\begin{array}{l}\text { Compatibility } \\
\text { of materials }\end{array}$ & $C_{m}=\frac{1}{u^{2}} \sum_{i=1}^{u} \sum_{j=1}^{u} c_{m}^{i, j}$ & $\begin{aligned} c_{m}^{i, j}: & \text { compatibility between the } \\
& i^{\text {th }} \text { and the } j^{\text {th }} \text { material; } \\
u: & \text { number of materials. }\end{aligned}$ & $\begin{array}{l}\text { (Ishii et al., } \\
\text { 1994) } \\
\text { (Pahl et al., } \\
\text { 2007) }\end{array}$ \\
\hline $\begin{array}{l}\text { Diversity of } \\
\text { materials }\end{array}$ & $D_{m}=\left(1-\sum_{i=1}^{u} c_{i} \log _{2} c_{i}\right)^{-1}$ & $\begin{array}{ll}c_{i}: & \text { concentration of the } i^{t h} \\
& \text { material such that } \sum_{i=1}^{u} c_{i}=1 ; \\
u: & \text { number of materials. }\end{array}$ & $\begin{array}{l}\text { (Rzeźnik et al., } \\
2008 \text { ) }\end{array}$ \\
\hline $\begin{array}{l}\text { Recyclability } \\
\text { of materials } \\
\text { (treatment } \\
\text { efficiency) }\end{array}$ & $R_{m}=\frac{1}{u} \sum_{i=1}^{u} \frac{m_{r c}^{(i)} \cdot m_{m}^{(i)}}{m_{t c}^{(i)} \cdot\left(m_{m}^{(i)}+m_{o m}^{(i)}\right)}$ & $\begin{array}{c}m_{r c}^{(i)}: \text { mass of the } i^{t h} \text { material } \\
\text { recycled by the chain; } \\
m_{t c}^{(i)}: \text { mass of the } i^{\text {th }} \text { material } \\
\text { treated by the chain; } \\
m_{m}^{(i)}: \text { mass of the } i^{\text {th }} \text { material } \\
\text { in the recycled fraction; } \\
m_{o m}^{(i)}: \text { mass of other materials } \\
\quad \text { in the recycled fraction. } \\
u: \text { number of materials. }\end{array}$ & $\begin{array}{l}\text { (Horta Arduin } \\
\text { et al., 2019) } \\
\text { (Grimaud, } \\
\text { 2019) }\end{array}$ \\
\hline $\begin{array}{l}\text { Product's } \\
\text { recyclability }\end{array}$ & $R_{p}=\frac{C_{m}+D_{m}+R_{m}}{n_{a l}}$ & $\begin{aligned} C_{m}: \text { compatibility of materials } \\
D_{m}: \text { diversity of materials } \\
R_{m}: \text { recyclability of materials } \\
n_{a l}: \text { number of aggregated } \\
\\
\quad \text { action levers. }\end{aligned}$ & $\begin{array}{l}\text { (Martínez } \\
\text { Leal, 2019) }\end{array}$ \\
\hline
\end{tabular}

\subsection{Design-from-EoL proposal}

\subsubsection{Method description}

The design-from-EoL proposal is the second module of RE-CYCLING. It aims to promote the use of recovered artefacts (i.e. used products, refurbished modules, recycled material, etc.) in the product's design, as it is a fundamental strategy for achieving a circular economy. Nevertheless, the convenience of using such artefacts has to be checked on different dimensions.

This approach is articulated in three steps: 
- $\quad$ Step 1: Selection of the recovered artefact. The material, part or module that could be replaced by a $(n+1)$-generation one is selected;

- $\quad$ Step 2: Evaluation of convenience indicators. Then, the advantages of using such an artefact are assessed in the technical, economic and environmental dimensions;

- Step 3: Evaluation of convenience index. The conveniences in the three dimensions are aggregated into a global score. A graph is proposed to allow designers to attest easily the convenience of using the EoL artefact and improve his product in a real circular economy perspective.

\subsubsection{Indicators description}

The indicators used in the RE-CYCLING's design-from-recycling module aim to assess the convenience of using a recycled material by defining which action levers need to be activated:

- The technical dimension is evaluated with two parameters:

- the quality of the recycled material which is expressed by the purity rate;

- and the supply reliability to avoid any secondary raw (i.e. recycled) material that might be difficult to supply;

- The economic dimension compares the prices of recycled materials to primary (i.e. virgin) ones;

- The environmental dimension compares the environmental impacts generated in the production of secondary raw materials to those of primary ones;

- Lastly, the global convenience index for using recycled material is defined as the average function of the previous parameters.

Indicators are all briefly recalled in Table 2 (from Martínez Leal et al. 2020). They are all constructed in the same way to be easily compared. If their score is inferior to the reference value (1), the recycled material is more convenient than the virgin one.

Table 2. RE-CYCLING's indicators used in the design-from-recycling proposal

\begin{tabular}{|c|c|c|}
\hline Indicator & Expression & Parameters \\
\hline $\begin{array}{l}\text { Technical } \\
\text { convenience of the } \\
\text { recycled material }\end{array}$ & $p_{\text {teu }}=2-\tau_{p} \cdot S_{r}$ & $\begin{array}{l}\tau_{p}: \text { purity rate of the recycled material; } \\
s_{r}: \text { supply reliability of the recycled material }\end{array}$ \\
\hline $\begin{array}{l}\text { Economic } \\
\text { convenience of the } \\
\text { recycled material }\end{array}$ & $p_{e c u}=\frac{v_{e c}}{v_{e c, r e f}}$ & $\begin{array}{l}v_{e c}: \text { economic value (recycled material); } \\
v_{e c, \text { ref }}: \text { economic reference value (virgin one). }\end{array}$ \\
\hline $\begin{array}{l}\text { Environmental } \\
\text { convenience of the } \\
\text { recycled material }\end{array}$ & $p_{\text {enu }}=\frac{1}{S} \cdot \sum_{k=1}^{s} \frac{v_{e n}^{(k)}}{v_{e n, \text { ref }}^{(k)}}$ & $\begin{array}{l}v_{e n}^{(k)}: \text { environmental value (recycled material) on the } \\
\quad k^{\text {th }} \text { impact category; } \\
v_{e n, r e f}^{(k)} \text { : environmental reference value (virgin material) } \\
\quad \text { on the } k^{\text {th }} \text { impact category; } \\
k: \quad \text { impact category number }(1 \leq k \leq s) .\end{array}$ \\
\hline $\begin{array}{l}\text { Convenience of } \\
\text { using the recycled } \\
\text { material }\end{array}$ & $C_{r m}=\frac{p_{t e u}+p_{e c u}+p_{e n u}}{n_{d}}$ & $n_{d}:$ number of aggregated dimensions \\
\hline
\end{tabular}

\section{CASE STUDY}

\subsection{Validation of design-for-recycling indicators}

\subsubsection{Case study description and validation criteria}

A previous study of the authors showed the implementation of RE-CYCLING's design-for-recycling proposal (Martínez Leal et al., 2020). However, the set of indicators was only confronted with the modular and upgradable Fairphone 2. Even though it is designed to be repaired and thus to increase its lifespan, this smartphone was found to be poorly recyclable. In this article, we intend to confront these previous results to other smartphones and confirm that similar results are obtained. 


\subsubsection{Case study considerations}

Two non-modular smartphones were selected to be compared to the Fairphone 2: the iPhone 3GS and the Nokia Lumia 620. They are both considered to be similar to the Fairphone and their components' BOM is available in the literature (Fontana et al., 2019; Singh et al., 2018).

Table 3. Smartphones components' BOM

\begin{tabular}{ll}
\hline Product & \multicolumn{1}{c}{ Components' BOM } \\
\hline Fairphone 2 & Display module (30.86\%): display frame; LCD display; display board. \\
& Core module (23.52\%): mainboard with electronic components and board-to- \\
& board connectors; antenna boards; volume button, power button, camera button \\
& assembly. \\
& Battery module (22.34\%): battery. \\
& Back cover (11.82\%): outer case; battery pressure pad and camera seal gasket. \\
& Bottom module (5.41\%): bottom module board; vibration motor; microphone; \\
& speaker; USB connector. \\
& Top module (3.82\%): top module board; front camera; receiver (speaker). \\
& Camera module (2.23\%): camera; camera board. \\
\hline iPhone 3GS & $\begin{array}{l}\text { Plastics (44.89\%); cover case and screws (37.84\%); battery (22.07\%); PCB's } \\
(14.97 \%) ; \text { screen (13.1\%); magnets (1\%); vibrator (0.89\%); LED lights }\end{array}$ \\
& $(0.02 \%) ;$ other $(0.22 \%) ;$. \\
\hline Nokia Lumia 620 & Plastic parts (26.5\%); battery (21\%); electronic parts (15.7\%); display (15.3\%); \\
& metal parts (13.1\%); other (32.4\%). \\
\hline
\end{tabular}

Depending on the product, BOMs can be defined at various levels such as modules, elementary parts, materials or even a combination of them all. Indeed, manufacturers are not required to provide a homogeneous BOM, nor is there a consensus in the literature. An extrapolation is then necessary to bring all the components to the same level. In our study, the following references were used to define the material composition of each component: PCB (Szałatkiewicz, 2014), LCD (Hischier and Lehmann, 2007), motor (Fraunhofer IZM, 2016), speaker (Güvendik, 2014), and LED (Chen and Tien, 2020). Figure 2 compares the resulting material compositions of the three smartphones.

In order to calculate the indicators, the following assumptions were made:

- $\quad$ Compatibility of materials: (i) The compatibility matrix was constructed using the following sources: metals (Reuter et al., 2018), plastics (Eco3e, 2016; Maier, 2009); (ii) plastics as secondary materials are considered to be compatible with metals; (iii) main materials were defined according to those recovered by the French WEEE recycling chain (Bleu Safran et al., 2017);

- Recyclability of materials: (i) The selected recycling scenario consists of shredding, physical preprocessing, metallurgy and plastics processing. (ii) The recycling rates were obtained from the following sources: metals (Fairphone, 2017) and the rest of materials (Deloitte Développement Durable et al., 2017); (iii) Due to lack of information, the purity level was set to 1 for all materials (note that this an ideal scenario and that in reality purity is more easily reached for ferrous materials than for the others). 


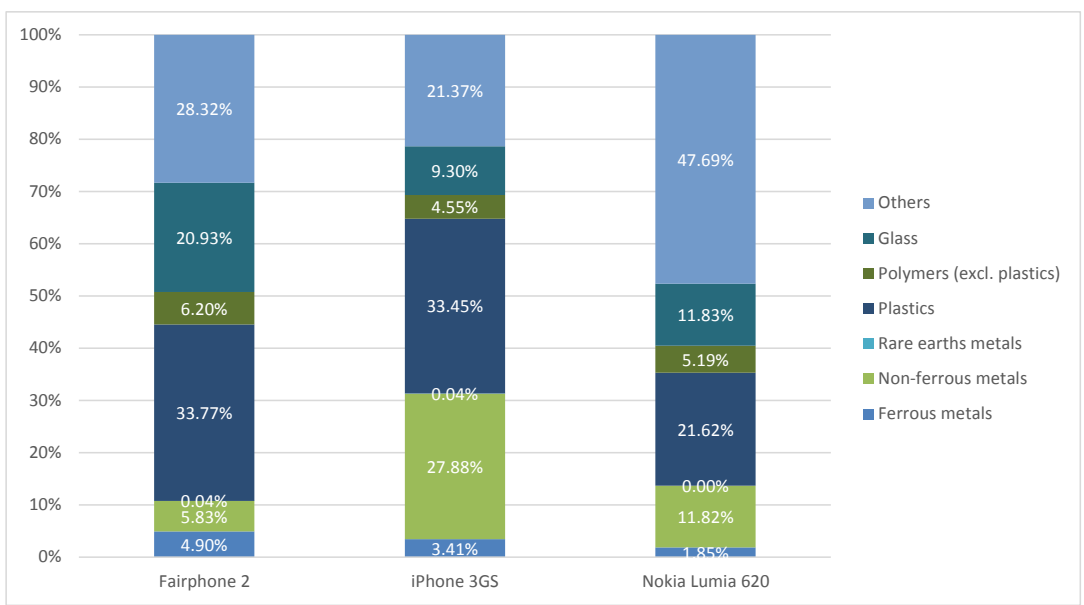

Figure 2. Material composition of the selected smartphones

\subsubsection{Results}

Indicators were assessed and results are presented in a recyclability score chart (see Figure 3).

Since material compositions were defined on published but incomplete information, several hypotheses have been proposed to complete the missing elements (e.g. using the material composition of a similar component when the actual composition is unknown, as presented in section 4.1.2). Therefore, note that results and analyses presented hereafter are only valid for our smartphones definition.

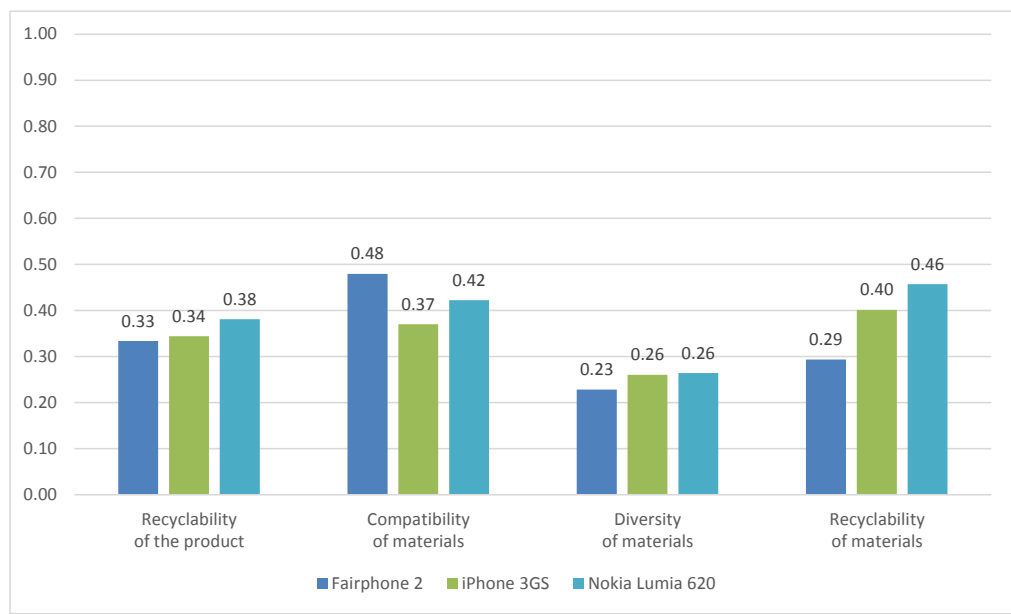

Figure 3. Recyclability score chart of the selected smartphones

It can be observed that all smartphones get a similar overall score (i.e. recyclability of the product) (about 0.35). This result complies with our validation criterion. Indeed, the indicators must provide a comparable recyclability score for all three smartphones as none of them was designed to be recycled. Concerning the materials' assessment, one can observe that the diversity of materials score gets a close similarity and the compatibility of materials, a fairly good one. This is also in line with what we expected as the three smartphones are considered similarly composed.

In contrast, an important gap exists for the recyclability of materials scores. This can be induced by the degree of detail in smartphones' BOM. Indeed as shown in Table 3, a very detailed component's BOM was found for the Fairphone 2, a fairly detailed one for the iPhone 3GS and a poorly detailed one for the Nokia Lumia 620. The influence of the degree of information on the assessment scores needs to be studied further.

\subsection{Validation of the design-from-recycling indicators}

\subsubsection{Case study description and validation criteria}

For the proposal to be validated, the convenience of using recycled materials must be clearly and easily determined. A previous study of the authors showed the implementation of RE-CYCLING's 
design-from-recycling proposal to assess the convenience of using recycled polycarbonate (Martínez Leal et al., 2020). The material choice was made on the basis that Fairphone states they use recycled polycarbonate, copper, and tungsten. Thus, the study simulates the circular economy scenario that Fairphone designers are presented with. The present paper aims at pursuing the aforementioned previous analysis by determining the convenience of using recycled copper from the French WEEE recycling chain. Different degrees of purity are considered.

\subsubsection{Case study considerations}

In order to calculate indicators, the following assumptions were made:

- For technical convenience, note that: (i) four degrees of copper purity were used (50, 80, 96 and 98\%) to match available economic data; (ii) the company responsible for supplying the recycled material was supposed to be checked and validated by the purchasing department. Supply reliability indicator was therefore set to 1 (see section 3.2.2);

- The economic convenience assessment was based on the data presented in Grimaud's study on the influence of quality on the resale price of copper (Grimaud, 2019);

- For environmental convenience, the impacts were calculated using the CML method with the functional unit being producing one kilogram of copper (virgin or recycled). One should note that the data used to calculate: (i) the environmental impact of the production of primary (i.e. virgin) raw materials come from the Ecoinvent 3 database; (ii) the environmental impact of the production of secondary (i.e. recycled) copper come from the Eco-systèmes and Récylum database (Bleu Safran et al., 2017); (iii) the selected impact categories are those used in the CML method. It is to be noted that no environmental data is available for the different grades of copper. Therefore, environmental convenience is the same for all four grades.

\subsubsection{Results}

All calculations done, convenience indicators are presented in Figure 4.

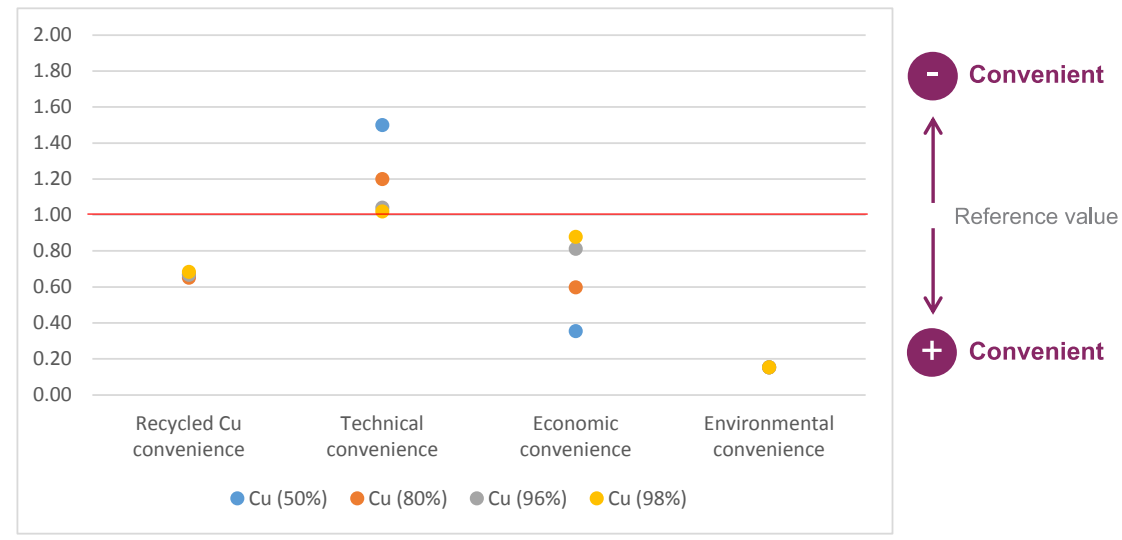

Figure 4. Recycled copper convenience assessment

It can be observed that recycled materials turn out to be economically and environmentally more convenient. On the other hand, the technical dimension is less convenient but this is to be expected as we considered a material with different grades of impurity. Overall, recycled copper proved to be more attractive than virgin material. Indeed, all global scores are below the reference value.

It is important to highlight that using recycled material might not always be more convenient. Indeed, it has been found in the aforementioned previous study that using recycled polycarbonate from the WEEE recycling chain was overall less interesting than virgin one.

The results of both studies confirm that this design-from-recycling tool can help designers assessing the advantages of integrating recycled materials in product's design and thus promoting a circular economy.

\section{CONCLUSIONS}

RE-CYCLING's ecodesign approach and the associated set of indicators were introduced and detailed in previous studies (Martínez Leal, 2019; Martínez Leal et al., 2020). There the design-for-recycling 
indicators were only confronted with one product (the modular and upgradable Fairphone 2) and the design-from-recycling indicators to a single material (recycled polycarbonate). The present paper aims to pursue these analyses and validate the proposed indicators.

In order to validate the design-for-recycling indicators, the recyclability of three smartphones was assessed. It was expected that indicators provide a comparable recyclability score as none of them was designed to be recycled. They behave as expected and can therefore be validated. Nevertheless, the influence of BOM's detail degree needs to be studied further.

In this regard, we strongly believe that a standardized BOM for each type of product is needed. Indeed, a homogeneous BOM by product typology would not only simplify the use of RE-CYLING, but also benefit any other eco-design tool or database.

In the meantime, the proposed indicators were constructed so they can be used for any artefact (product, module, elementary part, material, etc.). Thus, designers can use RE-CYCLING for any level of data and any degree of accuracy they wish to bring to their analysis.

It is also important to note that, in both practice and literature, product's recyclability is often assessed with mass preservation indicators as required by legislation (Leal et al., 2018). The proposed indicators differ from this conventional and widely accepted assessment. Indeed, they were constructed assuming that all materials have the same importance and so the same weight when building the aggregated index. It would be interesting to explore additional decision-making criteria such as technical, economic and environmental considerations. That would not only provide information on the hotspots with the lowest scores but also on the ones that will have a better impact on each of the aforementioned dimensions.

The convenience of using recycled materials in the manufacturing of smartphones was analysed to validate our design-from-recycling indicators. The case study has led to demonstrate that designers can easily identify the interest in using recycled material (even regardless of the purity of copper, in our case study). However, possible deterioration of the technical performance of the product caused by a low purity should be included in the technical assessment. A potential downcycling of materials should also be taken into account, from one generation to the next.

Lastly, we remind that this paper only focuses on validating RE-CYCLING's D2fR indicators. Thus, only recycling-related indicators were addressed. However, remember that RE-CYCLING is not only a recycling-centred approach as it can address all EoL options (i.e. functional, material and energy recovery), and can be also EoL stakeholders-centred. For more information on the indicators related to other EoL options, please refer to the aforementioned publication (Martínez Leal, 2019).

\section{ACKNOWLEDGEMENTS}

This research was funded by ADEME (French Environment and Energy Management Agency). The authors would like to thank EcoSD Network (French association encouraging collaboration between academic and industrial researchers in ecodesign fields) for their aid and support.

\section{REFERENCES}

Bleu Safran, Hugrel, C. and Palluau, M. (2017), ICV de La Gestion de Fin de Vie Des Matériaux Constitutifs Des Équipements Électriques et Électroniques, Synthèse, p. 93.

Chen, W.-S. and Tien, Y.-F.C. and K.-W. (2020), "Recovery of Gallium and Indium from Waste Light Emitting Diodes", Journal of the Korean Institute of Resources Recycling, pp. 81-88.

Deloitte Développement Durable, Deprouw, A., Jover, M., Chouvenc, S., ADEME and Fangeat, E. (2017), Rapport Annuelle Du Registre Des Déchets d'équipements Électriques et Électroniques, p. 132.

Eco3e. (2016), "Plastics", November, available at: http://eco3e.eu/en/base/plastics/ (accessed 3 October 2019).

European Parliament. (2008), Directive 2008/98/EC of the European Parliament and of the Council on Waste and Repealing Certain Directives, p. 28.

European Parliament. (2009), Directive 2009/125/EC of the European Parliament and of the Council Establishing a Framework for the Setting of Ecodesign Requirements for Energy-Related Products.

European Parliament. (2012), Directive 2012/19/EU of the European Parliament and of the Council on Waste Electrical and Electronic Equipment (WEEE), p. 34.

Fairphone. (2017), Fairphone's Report on Recyclability.

Fontana, D., Pietrantonio, M., Pucciarmati, S., Rao, C. and Forte, F. (2019), “A comprehensive characterization of End-of-Life mobile phones for secondary material resources identification”, Waste Management, Vol. 99, pp. 22-30. 
Fraunhofer IZM. (2016), Life Cycle Assessment of the Fairphone 2, Fraunhofer IZM, available at: https://www.researchgate.net/publication/311425397_Life_Cycle_Assessment_of_the_Fairphone_2.

Go, T.F., Wahab, D.A. and Hishamuddin, H. (2015), "Multiple generation life-cycles for product sustainability: the way forward", Journal of Cleaner Production, Vol. 95, pp. 16-29.

Grimaud, G. (2019), “Conception des scénarios de recyclage pilotée par l'évaluation des performances des procédés", 18 February.

Güvendik, M. (2014), From Smartphone to Futurephone: Assessing the Environmental Impacts of Different Circular Economy Scenarios of a Smartphone Using LCA.

Hischier, R. and Lehmann, M. (2007), Life Cycle Inventories of Electric and Electronic Equipment: Production, Use and Disposal. Part III - Electronic Devices, No. ecoinvent report No. 18, Swiss Centre for Life Cycle Inventories, Dübendorf.

Horta Arduin, R., Grimaud, G., Martínez Leal, J., Pompidou, S., Charbuillet, C., Laratte, B., Alix, T., et al. (2019), "Influence of scope definition in recycling rate calculation for European e-waste extended producer responsibility", Waste Management, Vol. 84, pp. 256-268.

Ishii, K., Eubanks, C.F. and Di Marco, P. (1994), "Design for product retirement and material life-cycle", Materials \& Design, Vol. 15 No. 4, pp. 225-233.

Leal, J.M., Pompidou, S., Charbuillet, C. and Perry, N. (2018), "Product Recoverability: A Review of Assessment Methods", Procedia CIRP, Vol. 69, pp. 710-715.

Lindkvist Haziri, L. and Sundin, E. (2020), "Supporting design for remanufacturing - A framework for implementing information feedback from remanufacturing to product design", Journal of Remanufacturing, Vol. 10 No. 1, pp. 57-76.

Lindkvist Haziri, L., Sundin, E. and Sakao, T. (2019), "Feedback from Remanufacturing: Its Unexploited Potential to Improve Future Product Design”, Sustainability, Multidisciplinary Digital Publishing Institute, Vol. 11 No. 15, p. 4037.

Maier, C. (2009), Design Guides for Plastics, Econology Ltd, p. 67.

Martínez Leal, J. (2019), Développement d'outils d'aide à la décision en conception pilotés par l'analyse multicritère de la valorisabilité du produit et l'outillage des lignes directrices d'écoconception pour la fin de vie, Thèse de doctorat, Ensam, Bordeaux, 19 December, available at: https://pastel.archives-ouvertes.fr/tel02939064.

Martínez Leal, J., Pompidou, S., Charbuillet, C. and Perry, N. (2020), "Design for and from Recycling: A Circular Ecodesign Approach to Improve the Circular Economy", Sustainability, Multidisciplinary Digital Publishing Institute, Vol. 12 No. 23, p. 9861.

Mathieux, F. (2002), Contribution à l'intégration de la valorisation en fin de vie dès la conception d'un produit . Une méthode basée sur l'évaluation multicritères de la recyclabilité du produit et sur l'identification de ses points faibles de conception, phdthesis, Arts et Métiers ParisTech, Chambéry, France, available at: https://tel.archives-ouvertes.fr/tel-00005689/document.

Maudet, C., Bertoluci, G. and Froelich, D. (2007), "Integrating plastic recycling industries into the automotive supply chain", available at: https://hal.archives-ouvertes.fr/hal-00719227 (accessed 21 August 2020).

Pahl, G., Beitz, W., Feldhusen, J., Grote, K.-H., Wallace, K. and Blessing, L.T. (Eds.). (2007), Engineering Design: A Systematic Approach, 3. ed., Springer, London.

Reuter, M., Schaik, A. and Ballester, M. (2018), "Limits of the Circular Economy: Fairphone Modular Design Pushing the Limits", World of Metallurgy - ERZMETALL, Vol. 71.

Rzeźnik, C., Rybacki, P. and Molińska, A. (2008), "Assessment of the effect of the material diversity of agricultural machines on their recyclability", Journal of Research and Applications in Agricultural Engineering, Vol. Vol. 53 No. nr 1, pp. 12-15.

Singh, N., Duan, H., Yin, F., Song, Q. and Li, J. (2018), "Characterizing the Materials Composition and Recovery Potential from Waste Mobile Phones: A Comparative Evaluation of Cellular and Smart Phones", ACS Sustainable Chemistry \& Engineering, American Chemical Society, Vol. 6 No. 10, pp. 13016-13024.

Szałatkiewicz, J. (2014), "Metals Content in Printed Circuit Board Waste", Polish Journal of Environmental Studies, Vol. 23 No. 6, pp. 2365-2369. 